\title{
Design and Implementation of E-Tendering System
}

\author{
Aye Thida \\ Information Technology Engineering \\ Technological University(Thanlyin), \\ Myanmar
}

\author{
Aye Thu Hlaing \\ Information Technology Engineering \\ Technological University(Taungoo), \\ Myanmar
}

\begin{abstract}
E-tendering is one of the information technology tools that has been highlighted by construction industry experts to assist in changing the industry's culture and improving its processes. E-Tendering System is an internet based process wherein the complete tendering process; from advertising to receiving and submitting tender-related information are done online. This enables firms to be more efficient as paper-based transactions are reduced or eliminated, facilitating for a more speedy exchange of information. Etendering Systems can significantly reduce the numbers of hours and bureaucracy to create and award a tender. The aim of this paper is to provide tendering services easily and conveniently for city-staff and company, to create tender for bidding their requirements and for the users who want to bid opening tender related to their company, to automate manual activities currently performed in the tendering process. E-tendering System can significantly improve the efficiency and time taken to complete a purchasing process, many of the activities listed above can be managed efficiently. It is implemented by Struts, Spring, Hibernate framework based on Web Application Features. Java platform provides all of the tools and technologies that are needed to build distributed web application. Java is the dominant Web programming language today, and is used extensively by the Open Source community. In this paper, Fedora redhat linux OS is used to implement the web design for E-tendering Services. This system is Web application system depends on this framework concept and uses Hibernate Query Language to test the database. With the achievement of this paper, it is easy to understand how to create E-tendering services with linux administration approaches.
\end{abstract}

Keywords: E-tendering; Open Source; Fedora redhat linux Operating System; Hibernate Query Language; Struts; Spring

\section{INTRODUCTION}

E-Tendering system is a web based application intended for online users for replacing the manual paper-based tender processes. The E-Tender system is to provide the interface between the tender buyers and the sellers on the internet. Etendering is the process where the physical tendering activity is carried out online using the internet and associated technologies. Our E-tendering system consists of four-Users: Admin, City Staff, Company and Citizen.

This system allows tender board Admin to manage tenders through a web site. Companies can submit bids online and upload documents. The companies can modify their bids till the tender bid submission closing by the admin. The Admin subsystem is to give services for city-staff (tender-board who create tenders. All the citizens can see the information of the published tenders by visiting our E-tendering web-site.

The main objective of this system is to provide tendering services easily and conveniently for city-staff and company. Admin must be to create, update, delete the tender and decide the winner for the tender. The current manual system the company has decided to automate the current system into the computer application as the website.

Company has an opportunity to bid the tender by putting the bidding price and the application document. And so process for registration and the searching the tenders becomes easy and fast. So the system helps to save the time at the both site. Other users can browse the tender-information and winner company information for all disclose tender (which means the winner company is chosen for that tender).

\section{ARCHITECTURE DESIGN}

This system is implemented by Struts, Spring and Hibernate framework based on Web Application Features. This is an open-source framework that in combination with standard Java Technologies like Java Servlets, Java Beans, and XML helps in effective development of web application. This system is Web application system depends on this framework concept and uses Hibernate Query Language to test the database.

\subsection{Advantage of Linux Operating System in Networking}

Linux is open source operating system first developed and released to the world by in 1991. Linux has been adapted to include support for non-Intel processor and even multiple processors, sophisticated TCP/IP networking facilities. And Versions of Linux are now available for many computer models. Linux is distinguished from many popular operating systems in three important ways. The first is that Linux is a cross-platform operating system. The second fact is that Linux is free: Linux is free or nearly free in an economic sense. And then Linux and many Linux applications are distributed in source form. This makes it possible for users to modify or improve Linux. Because of this freedom, Linux is being constantly improved and updated. The key advantage of Linux operating system is network configuration. The most important and fundamental configuration for a server is network configuration [1].

\subsection{Functional Requirement}

The online tendering system consists of four sub-systems. One is the City Staff subsystem that all cities will use this system to create tender for bidding their requirements. One is the Company Subsystem that they can bid opening tender related to their company. Another is the Citizen that they can see which company is winner after tender disclosed. Another one is the Admin that they can control all of the system and can decide the winner after tender closed. 


\section{SYSTEM DESIGN}

There are four main processes in e-tendering system. The overall system design for proposed system is shown in Figure 1 and actor in use case diagram is shown in Table 1.

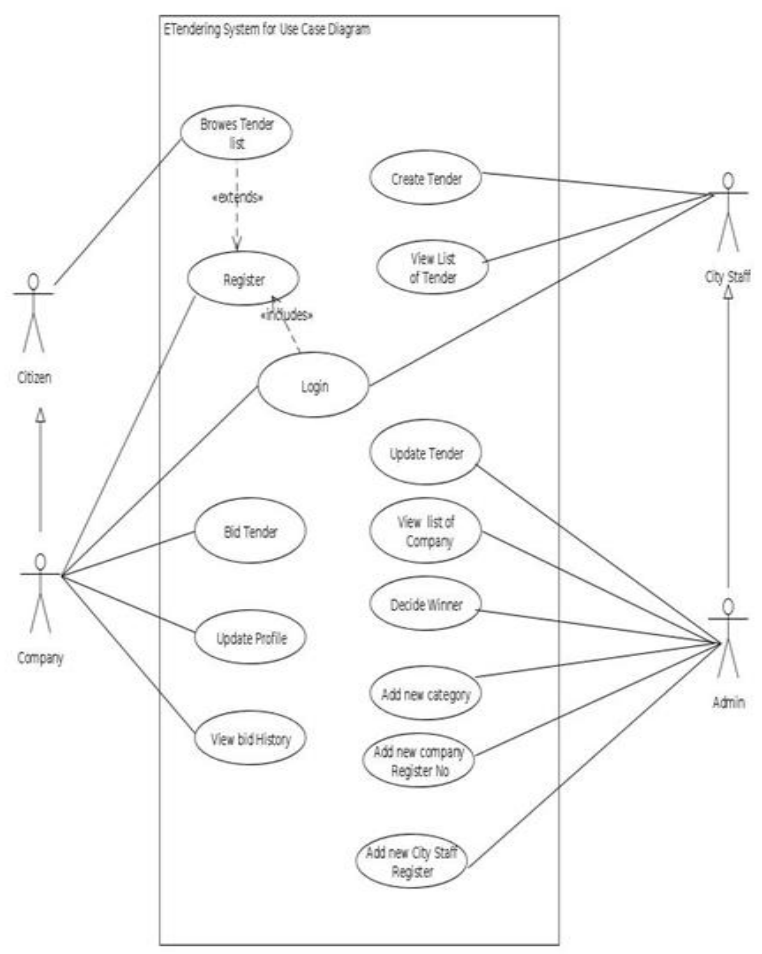

Figure 1. Use Case Diagram for E-tendering System

Table 1. Actor in Use Case Diagram

\begin{tabular}{|l|l|l|}
\hline No & User & Description \\
\hline 1 & Company & $\begin{array}{l}\text { Company must be view tender list the } \\
\text { E-Tendering system to make and create } \\
\text { tender by making registration to the } \\
\text { system. }\end{array}$ \\
\hline 2 & City Staff & $\begin{array}{l}\text { City Staff must be registered user, } \\
\text { authorized person in your universities } \\
\text { or Companies who can make tender } \\
\text { submission. }\end{array}$ \\
\hline 3 & Admin & $\begin{array}{l}\text { Admin must be registered user, } \\
\text { authorized person in your universities } \\
\text { or companies who has the admin role } \\
\text { and this system to choose winner } \\
\text { company. }\end{array}$ \\
\hline 4 & Citizen & $\begin{array}{l}\text { All citizens in the country who view } \\
\text { tender list and winner company list of } \\
\text { disclosed tender. }\end{array}$ \\
\hline
\end{tabular}

\subsection{Database Design}

E-Tendering system needs four users in general. The following things are that they can do in the system.

User can do: Registration as member, Login if member, Search tender by category/ subcategory, View Bid History, View Profile, Update Profile Logout.
City Staff can do: Login, Create Tender, View List of Tender, Update City Staff Profile, Logout.

Admin can do: Login, List of Tender, Add category/ subcategory, Create Tender, Update Tender, List of City Staff, List of Company, Add City Staff, Add Company Registration Number, Decide Winner, List of Winner, J Free Chart, Logout.

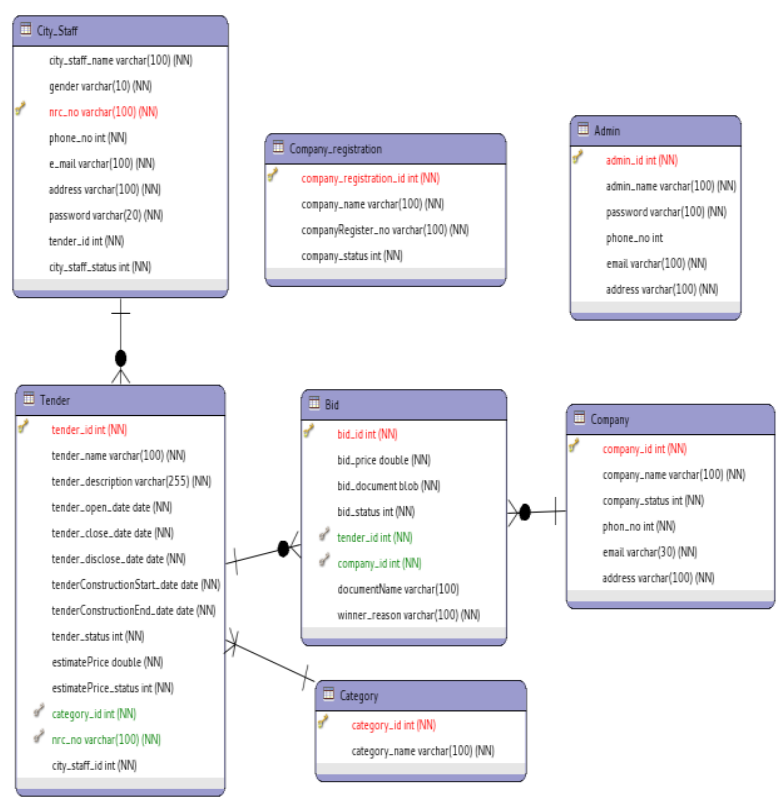

Figure 2. Entity Relationship Diagram for E-Tendering System

\subsubsection{CRUD Matrix}

CRUD stand for Create, Refer, Update and Delete is four basic functions of persistent storage and it is used for bottom-up data modeling to analyze when and what events happens to each entity and its attribute. CRUD matrix for e-tendering system is shown in Table 2.

Table 2. CRUD Matrix for E-tendering System

\begin{tabular}{|c|c|c|c|c|}
\hline User & : & 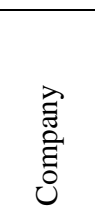 & $\frac{\Xi}{\Xi}$ & 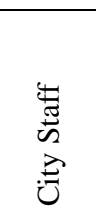 \\
\hline $\begin{array}{l}\text { company } \\
\text { registration }\end{array}$ & - & - & $\begin{array}{c}\mathrm{C}, \mathrm{R}, \mathrm{U}, \\
\mathrm{D}\end{array}$ & - \\
\hline city-staff & - & - & $\begin{array}{c}\mathrm{C}, \mathrm{R}, \mathrm{U} \\
\mathrm{D}\end{array}$ & $\mathrm{R}, \mathrm{U}$ \\
\hline Bid & - & $\mathrm{C}, \mathrm{R}$ & R,D & $\mathrm{R}$ \\
\hline tender & $\mathrm{R}$ & $\mathrm{R}$ & R,U,D & $\mathrm{C}, \mathrm{R}, \mathrm{U}$ \\
\hline category & $\mathrm{R}$ & $\mathrm{R}$ & $\begin{array}{c}\mathrm{C}, \mathrm{R}, \mathrm{U}, \\
\mathrm{D}\end{array}$ & $\mathrm{R}$ \\
\hline company & - & $\mathrm{C}, \mathrm{R}, \mathrm{U}$ & R,D & $\mathrm{R}$ \\
\hline
\end{tabular}




\section{IMPLEMENTATION OF PROPOSED SYSTEM DESIGN}

When the user is entered the client URL of the application in the browser, the home page of the application will be occurred where search menu bars and the list of open status tenders are displayed.

User can search the desired tender in three ways; by choosing the category or by selecting open date or close date as shown in Figure 3. The user can see the tender name, tender category, status, open date, close date and Disclose date in the list of tender. A link to show the tender detail information is also provided.

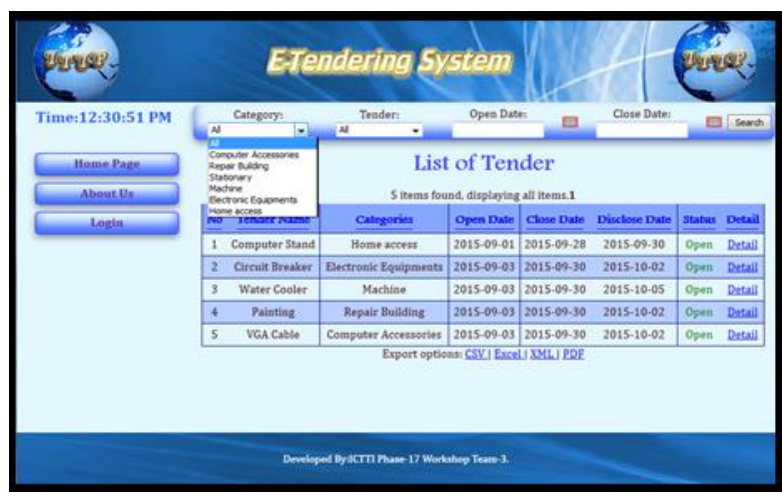

Figure 3. Citizen Home page with Search Menu Bar

The open tender detail page is shown in Figure 4. The user can view the detail information of specific tender without register for login. Whenever user wants to bid the tender, he has to login as the first task. If he click "Bid" button, login page will appeared as shown in figure 5 .

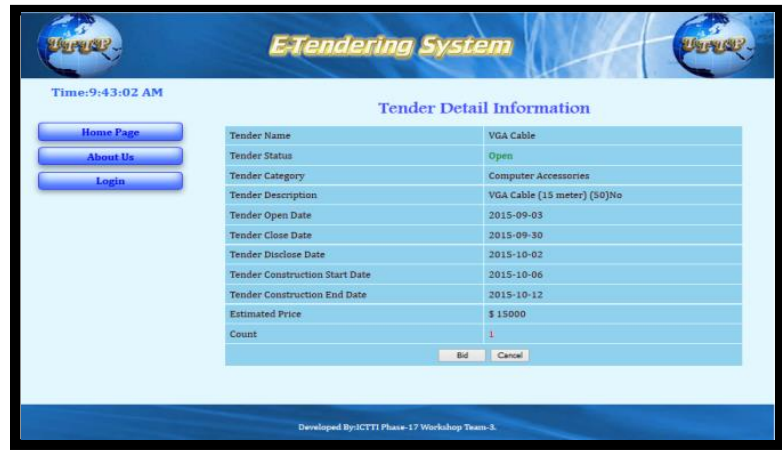

Figure 4. Open Tender Detail Page

A new user can make registration by clicking the registration link as shown in Figure 5. In Figure 6, the “***" beside the label indicates the required field for successful registration on the site.

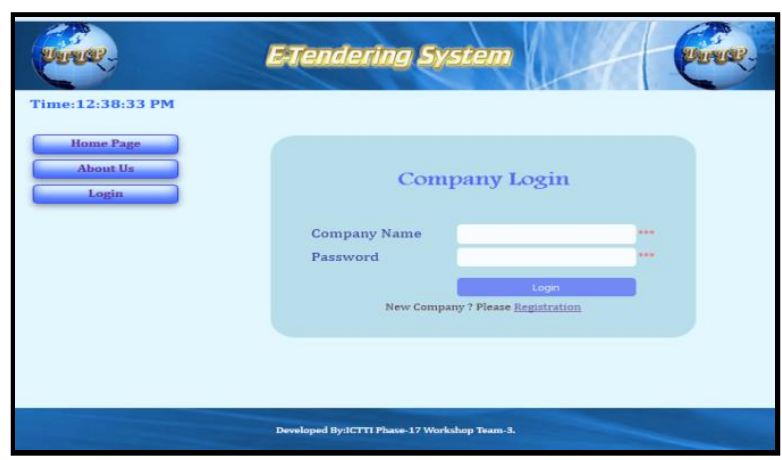

Figure 5. Company Login Page for Bid

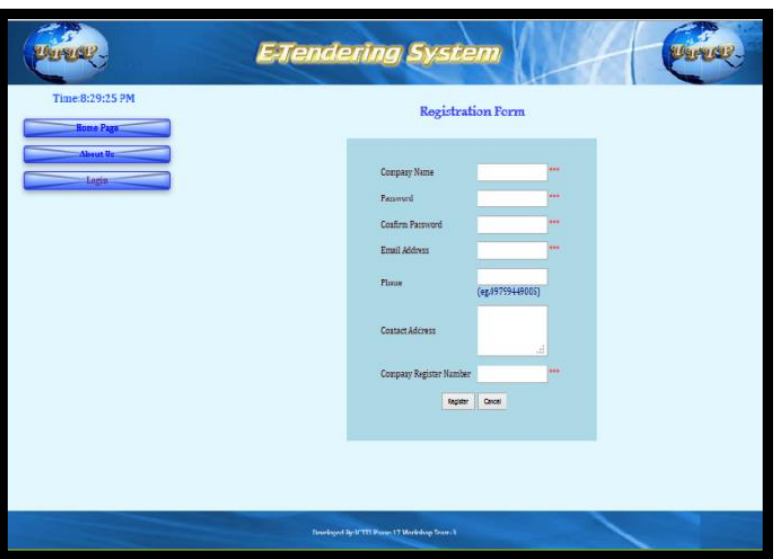

Figure 6. Company Registration Page

If the user fills the required information completely and correctly, user can click the "Register" Button and confirmation page will appear and registration successful page will be displayed as shown in Figure 7.

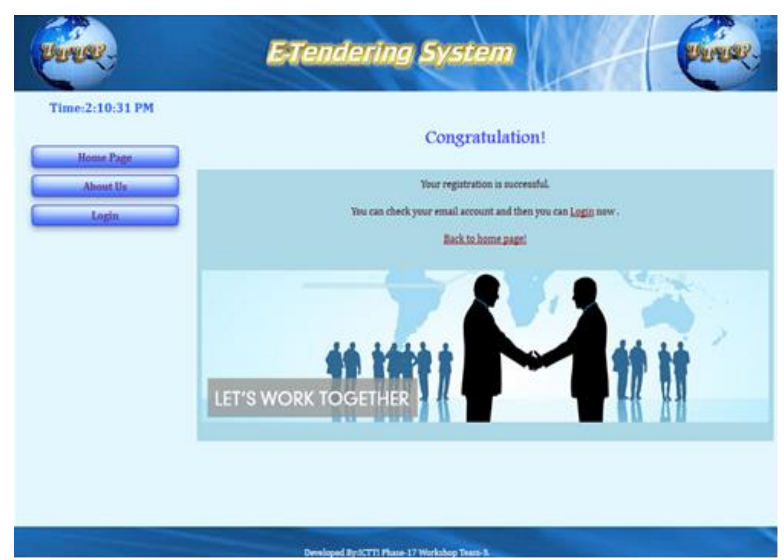

Figure 7 - Citizen Registration Successful Page

When the user clicks the save button, the user information is submitted for registration and our system reply the congratulation mail to successfully registered company and will displayed "Congratulation Message".

The company (user) can enter into the system by inserting correct login name and password. If the login process is success, the user can see the company home page of his/her 
account and the company user can view bid history, view their profile and update their profile as shown in Figure 8.

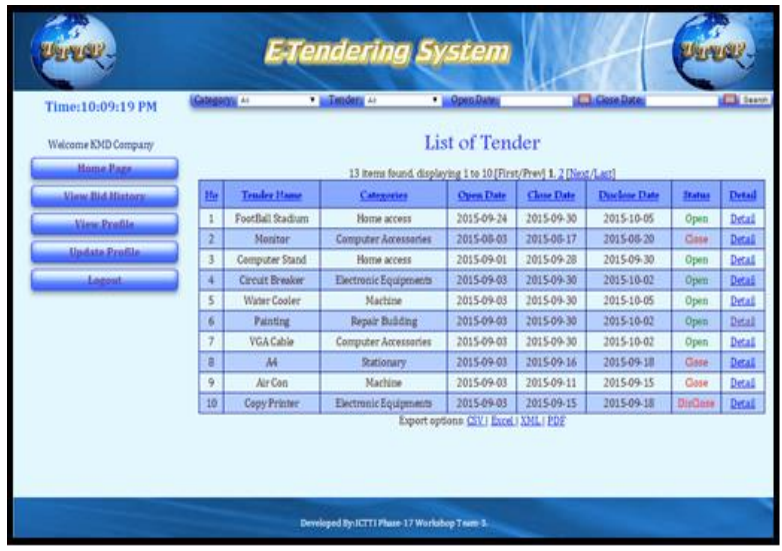

Figure 8. Welcome Page for Company

In the list of tender, a detail link will show the detail information of tender. In detail information, "count" shows how many number of company already bid this tender. For further information, company can see the list of company through the count link.

For disclosed tenders, the system will describe the winner in the list of company as shown in Figure 9. The company (user) can see the "Bid" button to bid the open tender. And then, the user can bid the interested tender by offering bid price and uploading document.

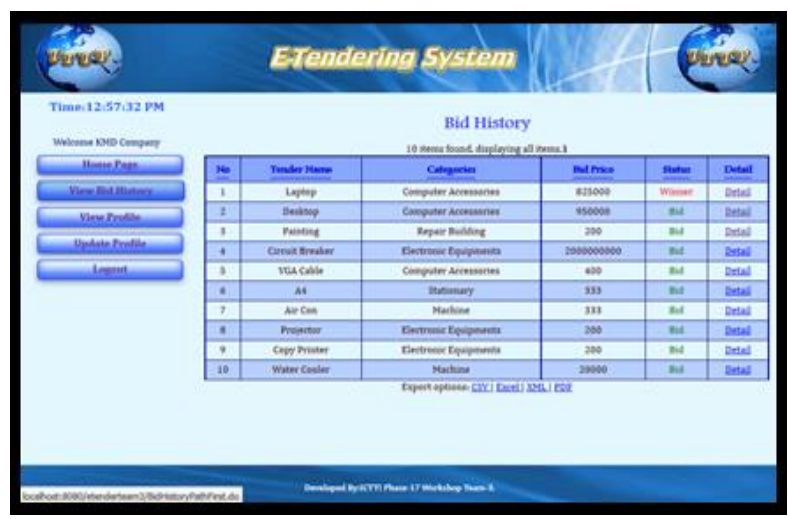

Figure 9. Bid History Page for Company

At the city staff home page, the user who is the city staff can see latest 10 tenders list with their status and he/she can also click "First", "Prev", "Next", "Last" link to see another tenders. City staff can search tender by Category Name, Tender Name, Tender Open Date and Close Date. City staff can view each interested tender detail information by clicking "Detail" link. The city staff can view the list of tenders that he/she created by clicking "View List of Tender" link. The city staff can also update information of tender when the status is in "Create" state as shown in Figure 10.

Figure 11. Admin Home Page

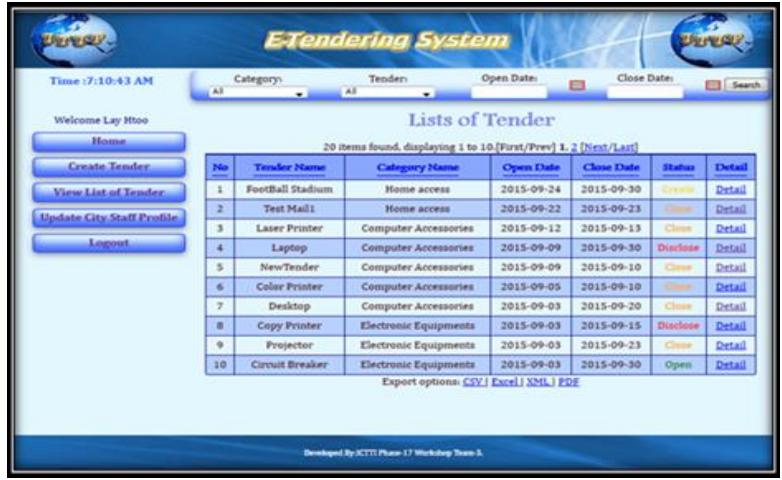

Figure 10. City Staff Home Page

The admin can do all the operations of city-staff together with admin operations such as: add company information, add new category and city staff information as shown in Figure 11. Moreover, Admin can block the black list company and the dismissed city staff and also unblock them if needed. Admin can also view the city-staff member list. Admin can see the all list of tender as available in our system. Admin can update and delete tender when tender is "create" status through the "List of Tender" link. Admin can retrieve and view the chart for tender report by year through 'Jfree Chart' link as shown in Figure 12.
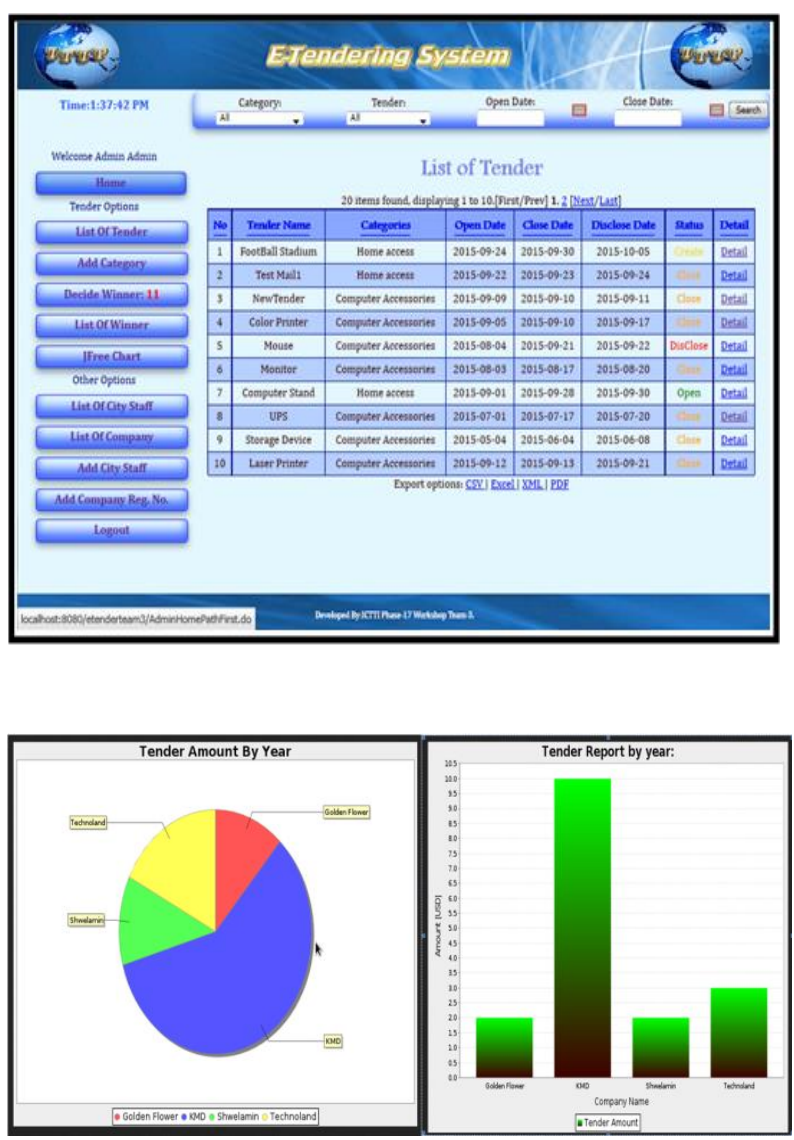

Figure 12. Pie Chart and Bar Chart for Tender Report

\section{CONCLUSION AND DISCUSSION}

The e-tendering system is a web based system that can be accessible by all city-staff to prepare their tenders and publish 
them using the system. Moreover, the companies can also view the available tenders on-line and submit their bid on-line. Winner Company can receive an e-mail from our e-tendering system. Furthermore, all the citizens who do not involve in tendering process can view the tender information and winner information of the tenders. The system makes the tendering process more convenient for both the city-staff and companies. All the necessary data for the tendering process is stored on an RDBMS at the server side. The server processes all of user requests based on the user type and give appropriate response according to the requests. This system was designed into four modules; first one for the client who wishes to access the system as viewers (citizens), the second one is bidders (company). Third is for the city-staff who can create the tenders and fourth module is the admin who manage the tenders and city-staff. The e-tendering system is the most widely used and popular in this current day. The system can be used easily and have many benefits. In the next year, the system can be widely expressed and convenient for tender management process for tender board staff and admin and bidding process for companies.

\section{ACKNOWLEDGMENTS}

The author would like to thank to her family and partners who have contributed towards development of this work.

\section{REFERENCES}

[1] Y.Kogure, T.D. Phyu, E.E. Khin, 2008, "Fundamental Linux", ICTTI Union of Myanmar.

[2] Betts, M., Black, P., Christensen, S., Dawson, E., Du, R., Duncan, W. Foo, E. \& Gonzalez, J. (2006) Towards Secure and Legal E-tendering. IT con, Vol.11, Special Issue e-commerce in construction, pg. 89-102.

[3] BCIS (2006) 2006 eTendering Survey Report, RICS, 2006.

[4] BCIS (2009) 2009 eTendering Survey Report, RICS, 2009.

[5] Booty, F. (2004) "Does E-Tendering Represent the Future Marketplace?" Available at: www.rics.org/ ricsms/bin/show?class=Feature \& template $=$ /includes/feat ure (Accessed 16 September 2008).

[6] Brown, C. (2006) The Role of Electronic Documentation Improving Production Line Efficiencies. Available at: https://aerade.cranfield.ac.uk/bitstream/1826/1625/1/ Brown-2006.pdf (Accessed 10 October 2008).

[7] Horsman, L. (2001) "Electronic Tendering System from the OGC". Available at: www.sourceuk.net/ articles/a01619.html (Accessed 10 October 2008) 